\title{
Pattern of Childhood Fractures in a Developing Country
}

\author{
A Saw, FRCS (Ed), N Fadzilah, BBEng (UM), M Nawar, MS Orth (UM), YP Chua, MS Orth (UM) \\ Department Orthopaedic Surgery, University Malaya Medical Center, Kuala Lumpur, Malaysia
}

\begin{abstract}
Introduction: Trauma is a major cause of childhood morbidity, and pattern of fractures in children is related to socioeconomic and environment factors. We conducted this study to look at fracture pattern of children in a developing country. Material and Method: Children aged 12 and below who attended paediatric orthopaedic out-patient clinic between July 2009 and March 2010 were enrolled for the study. Information was collected by interview that was based on a questionnaire. Results: There were 260 children in the study, and $72.3 \%$ were boys. The most common bone fractured was the radius and/or ulnar (41.9\%), followed by the humerus $(27.7 \%)$ and tibia/fibula (7.7). Most common place for fracture to happen was at home $(35.5 \%)$, followed by in the parks $(17.3 \%)$ and at school $(15.7 \%)$. Road traffic accident only contributed $9.2 \%$ of all the fractures. Of the 25 fractures due to road traffic accidents, 16 involved the use of vehicles. About one third $(36.73 \%)$ of the injuries were not witnessed. One quarter $(24.9 \%)$ were witnessed by parents and one fifth (17.1\%) witnessed by siblings. Conclusion: Upper limb are more commonly fractures than lower limbs. Measures to reduce the problem should start at home by creating higher awareness on injury prevention among the parents.
\end{abstract}

Key Words:

Fracture, Children, Developing Country, Pattern

\section{INTRODUCTION}

In many developed countries, trauma is a major cause for childhood morbidity and admission to hospitals ${ }^{1,2}$. The types of fractures seen in children are related to age, sex, socioeconomic and environment factors ${ }^{3}$. To date, most of the information on this subject appearing in the literature is based on studies conducted on a Western population ${ }^{2,4,5}$.

In developing countries, children generally contributed a higher proportion of the total population. Although one would expect more admissions due to medical conditions like infection and gastroenteritis, trauma related problems are still common due lack of safety awareness and poorly equipped public recreational or sports facilities ${ }^{6}$. Information on childhood fractures in South East Asia region is very limited. Iqbal published one of the few studies conducted in
Malaysia in 1974, but there has not been a recent update on this subject ${ }^{7}$.

We therefore designed this study to investigate the pattern of fractures in children based on an urban community in South East Asia. We also hoped to identify fracture patterns and factors that may have contributed towards injury so that preventive measures can be considered.

\section{MATERIALS AND METHODS}

Children aged 12 or below whom sustained fracture(s) between July 2009 and March 2010 were enrolled for this study. They were identified from the paediatric orthopaedic follow up clinic and the parents or caretakers were interviewed by one of the authors using a questionnaire. Radiological images were later retrieved and reviewed to confirm the fracture site. Children with chronic diseases or those with pathological fractures were excluded. This report will describe the factors that became evident from the data collected related to many types of fractures studied. Environmental and socio-economic factors also were grouped and analyzed. The study was approved by the ethical committee of the institution.

\section{RESULTS}

A total of 260 children presented with fracture during the study period and all the parents or caretakers agreed to participate in the study. There were 189 boys $(72.3 \%)$ and 71 girls $(27.3 \%)$, giving a male to female ratio of $2.7: 1$. Mean age was 8.0 years old. There were 155 Malays (59.6\%), 77 Indians (28.6\%), 27 Chinese (10.4\%) and one Indonesian $(0.4 \%)$. The most common bones treated for fracture were the radius and/or ulnar $(41.9 \%)$, followed by the humerus $(27.7 \%)$ and tibia/fibula (7.7\%) (Table I).The fractures involved the right limb in 132 children $(50.8 \%)$ and the left limb in 113 children $(43.5 \%)$. In the remaining 15 children $(5.8 \%)$, the fractures were either bilateral or centrally located.

The fractures were sustained at home in 92 children (35.4\%), at parks in 45 children (17.3\%) followed by at school in 41 children $(15.7 \%)$ (Table II). Road traffic only contributed $9.2 \%$ of all the fractures. For fractures which occurred at 
Table I: Distribution of bones involved in the study

\begin{tabular}{|lrc|}
\hline Bone Fractured & No. & Percentage (\%) \\
\hline Radius Ulna & 109 & 41.92 \\
Humerus & 72 & 27.69 \\
Tibia Fibula & 20 & 7.69 \\
Femur & 19 & 7.31 \\
Clavicle & 19 & 7.31 \\
Others & 21 & 8.08 \\
Total & $\mathbf{2 6 0}$ & $\mathbf{1 0 0 . 0 0}$ \\
\hline
\end{tabular}

Table III: Types of flooring in those who fell at home from less than body height

\begin{tabular}{|lrc|}
\hline Types of Flooring & No. & Percentage (\%) \\
\hline Cement & 10 & 32.26 \\
Tiles & 6 & 19.35 \\
Linoleum & 5 & 16.13 \\
Marble & 5 & 16.13 \\
Parquet/Wood & 2 & 6.45 \\
Others & 3 & 9.67 \\
Total & 31 & 100.00 \\
\hline
\end{tabular}

Table V: Pattern of combined income of both the parents

\begin{tabular}{|lrc|}
\hline Combined Income RM & No & Percentage (\%) \\
\hline$<1000$ & 45 & 17.31 \\
$1001-3000$ & 127 & 48.85 \\
$3001-5000$ & 47 & 18.08 \\
$>5001$ & 39 & 15.00 \\
Uncertain & 2 & 0.77 \\
Total & 260 & 100.00 \\
\hline
\end{tabular}

home, most of them occurred in the living room and bedroom. For the 31 fractures resulting from fall while running (from a level less than body height) at home, ten $(32.3 \%)$ were on a cement floor, while tiles, linoleum and marble floorings were associated with five to six fractures each (Table III). The most common place of injury in school was in the field $(20.4 \%)$, followed by at the stairs $(18.2 \%)$. Of the 25 fractures due to road traffic accidents, the road in the housing estates (44.0\%) was the most common site of incident. Sixteen of these fractures involved the use of vehicles; six children were riding bicycles $(33.3 \%)$, six were passengers in cars $(33.3 \%)$ and four were pillion rider on motorcycles $(22.2 \%)$.

Only three children $(1.2 \%)$ were initially seen by traditional healer before coming to hospital. There was no case of suspected non accidental injury in this study. About one third $(36.73 \%)$ of the injuries were not witnessed. About one quarter $(24.9 \%)$ were witnessed by parents and one fifth $(17.1 \%)$ witnessed by siblings.

All the parents were educated up to a primary school level. About $65.0 \%$ of the fathers and also the mothers completed either lower or upper secondary education. Seventy of the mothers $(22.7 \%)$ received higher than secondary school
Table II: Place or nature of injury

\begin{tabular}{|lcc|}
\hline Place of Accident & No. & Percentage (\%) \\
\hline Home & 92 & 35.38 \\
Parks & 45 & 17.31 \\
School & 41 & 15.77 \\
Private Premises & 31 & 11.92 \\
Sporting Events & 26 & 10.00 \\
Road Traffic Accident & 24 & 9.23 \\
Others & 1 & 0.38 \\
Total & $\mathbf{2 6 0}$ & $\mathbf{1 0 0 . 0 0}$ \\
\hline
\end{tabular}

Table IV: Witness of injury that resulted in fracture

\begin{tabular}{|lrc|}
\hline Witnesses of Injury & No. & Percentage (\%) \\
\hline Parents & 61 & 24.90 \\
Siblings & 42 & 17.14 \\
Teachers & 21 & 8.57 \\
Relatives & 15 & 6.12 \\
Guardians & 7 & 2.86 \\
Others & 24 & 9.23 \\
No witness & 90 & 36.73 \\
Total & 260 & 100.00 \\
\hline
\end{tabular}

education compared to only 59 of the fathers (26.9\%). In seven of the cases educational level of the parents could not be determined because the caretakers were not sure about this information. About one-half (48.9\%) of the families had a combined monthly family income of between MYR 1000 to MYR 3000 (USD 300 to 900) per month. In 17.3\% of the cases, the parents earned less than MYR 1000, while in $15.0 \%$ of cases they earned more than MYR 5000 (USD 1500) every month (Table V). We did not investigate individual contributions by each parent.

\section{DISCUSSION}

In our study, the boys outnumbered girls by more than two times (2.71: 1). Male predominance is commonly reported in childhood fractures ${ }^{2,8,9}$ although in some studies the difference may not be so obvious ${ }^{6}$. The forearm including the wrist was the most common site of the fractures which was consistent with other reports ${ }^{2,8}$. The rate of fracture in the other bones was more variable depending on type of classification and upper age limit of children. The rate of tibia and fibula fractures was relatively low $(7.7 \%)$ in this study. Deakin et al showed that fracture in the lower limbs which mainly contributed by distal tibia, tibia shaft and ankle peaked between ages of 12 to 16 years old. The children in our series were all below 12 years old ${ }^{2}$.

The most common place where the injuries occurred was at home $(35.4 \%)$. However, the rate is much lower than those reported by studies from India that ranged from $47.0 \%$ to $60.8 \%{ }^{6,8}$. On the other hand, Deakin et al reported that domestic accidents contributed only $2.9 \%$ of all upper limb 
and $5.0 \%$ of all lower limb fractures in Nottingham, England $^{2}$. The low awareness of fracture prevention in the home in developing countries may have contributed to this finding. It is also possible that children in Malaysia spent more time at home due to the lack of public recreational or sports facilities. Nations with more advanced economic achievement and higher level of industrialization are usually considered as developed countries, and they generally have higher rate of injuries in playground or sports activities ${ }^{10}$. A more detailed study into this aspect may provide us with information that may be helpful to reduce the risk of fractures at home. Cement floors are very common in flats or apartments as well as low and medium cost terrace houses. These are the common types of housing that are found in the urban area of Malaysia. Although twice as many falls / fractures happened on cement floor compared to any others types of floorings, we were not able to compare their relative risk. Road traffic accidents contributed $9.2 \%$ of all fractures, and about one third of them were associated with the use of bicycles. Injury prevention gears are not popular in developing countries as it is not compulsory by the local law. Moreover, bicycle lanes or public playground with bicycle paths are not available in most developing countries.

Seeking traditional medicine practitioners for fracture manage used to be a common practice in Malaysia, but the popularity has declined over the last 10 years. Only $1.2 \%$ of parents mentioned that they went for traditional management before deciding to come to the hospital. This practice is still relatively popular in some other regions ${ }^{6,9}$, and probably in the rural areas of this country. Adult supervision of young children is a major problem in the urban areas of developing countries because both parents may be working ${ }^{6}$. The fact that more mothers achieved a higher level of education than the fathers suggested that many mothers may also be working to support the family. House maid, grand-parents or the elder siblings were usually entrusted with the care of their younger siblings, and they may not be effective. The combined salary of MYR 1000 / USD 300 is generally adequate to support a small family in the urban area. However, with more children this may not be adequate, especially for an extended family. Therefore, preventive measures to reduce the rate of fractures in the urban community may have to be implemented by the government through improvement of public facilities and awareness campaigns.

\section{CONCLUSION}

Fractures in children in urban areas of a developing country may contribute significant morbidity to the community and burden to health resources. Measures to reduce the problem should start at home with higher awareness in injury prevention among the parents. In addition, the government should also play an important role in disseminating injury prevention awareness campaigns. They also should be active in implementing programs to improve the quality and availability of well designed public recreational and sports facilities.

\section{ACKNOWLEDGEMENT}

We would like to thank Nur Ain Iftitah, Chua Mei Leng and Chin Mee Feng for their contribution in data tabulation and preparation of the manuscript. We acknowledge the financial support rendered by University Malaya through University Malaya Research Grant code no: RG106/09HTM 


\section{REFERENCES}

1. Brudvik C, Hove LM. Childhood fractures in Bergen, Norway: identifying high-risk groups and activities. J Pediatr Orthop 2003; 23: 629-34.

2. Deakin DE, Crosby JM, Moran CG, Chell. Childhood fractures requiring inpatient Management. Injury 2007; 38: $1241-46$.

3. Landin LA. Fracture patterns in children. Analysis of 8,682 fractures with special reference to incidence, etiology and secular changes in a Swedish urban population 1950-1979. Acta Orthop Scand Suppl 1983; 202: 1-109.

4. Cooper C, Dennison EM, Leufkens HG, Bishop N, van Staa TP. Epidemiology of childhood fractures in Britain: a study using the General Practice Research Database. J Bone Miner Res 2004; 19(21): 1976-81.

5. Jones IE, Cannan R, Goulding A. Distal forearm fractures in New Zealand children: annual rates in a geographically defined area. N Z Med J 2000; 113(1120): 443-5.

6. Tandon T, Shaik M, Modi N. Paediatric trauma epidemiology in an urban scenario in India. J Orthop Surg (Hong Kong) 2007; 15(1): 41-5.

7. Iqbal QM. Long bone fractures among children in Malaysia. Int Surg 1974; 59(8): 410-5.

8. Rennie L, Court-Brown CM, Mok JY, Beattie TF. The epidemiology of fractures in children. Injury 2007; 38: 913-22.

9. Verma S, Lal N, Lodha R, Murmu L. Childhood Trauma Profile at a Tertiary Care Hospital in India. Indian Pediatr 2009; 46: 168-71.

10. Loder RT. The demographics of playground equipment injuries in children. J Pediatr Surg 2008; 43(4): 691-9. 